\title{
TRANSFORMASI PERPUSTAKAAN UNIVERSITAS AIRLANGGA SEBAGAI "AVAILABLE SPACE" : UPAYA MENINGKATKAN DAN MENDUKUNG PEMBELAJARAN MAHASISWA GENERASI NET
}

=

\author{
Sulistiorini
}

\begin{abstract}
Abstrak
Perpustakaanperguruantinggisaat initidak hanyadituntut untuk mengikutiperkembanganteknologiinformasidankomunikasi saja tetapi juga kebutuhan pengguna yang perlu kita perhatikan. Tanpa mengetahui kebutuhan mereka,perpustakaan tidak bisa eksis (tertinggal) dalam menghadapi perubahan peradaban yang begitu cepat. Perpustakaan perguruan tinggi harus bertransformasigunamemenuhikebutuhanpengguna, denganmenyediakan"availablespace” sebagaimanayangdisampaikan Bapak Ainun Na'im dalam acara workshop FK2PTN di Pangkal Pinang. Jauhsebelumnya Perpustakaan Universitas Airlangga Surabayatelahmelakukantransformasidengan “availablespace” sepertiruangdiskusi, ruanglobby, ruang Parlinah Moedjiono. Metode penulisan artikel ini menggunakan analisis deskriptif adalah menganalisis data dengan cara mendeskripsikan atau menggambarkan data yang telah terkumpul sebagaimana adanya tanpa bermaksud untuk membuat kesimpulan yang berlaku umum atau generalisasi. Dari pengamatan penulis, pengguna yang "generasi net" memiliki pola belajar yang lebih aktif dapat dilihat dariruang-ruangpublik yangtersediadi Perpustakaan Unair. Mereka cenderungmenuntut untuk lebih cepat danmudah dalam memperoleh informasiserta ruangyang khusus untuk bisa mengeksplorminat dan bakat mereka. Sehinggaruang-ruang publik tersebut tidak pernah sepi oleh kegiatan-kegiatan mereka.
\end{abstract}

Kata kunci: available space, net generation, public space private space, digital native

\section{PENDAHULUAN}

Pengertian perpustakaan secara mendasar adalah gedung atau tempat yang memiliki tugas mengadakan, mengumpulkan, mengolah, menyimpan, dan menyebarluaskan informasi kepada masyarakat. Seiring dengan perkembangan teknologi informasi keberadaan perpustakaan mengalami transformasi, penambahan atau perubahan baik secara fisik maupun konten. Perubahan fisik dititikberatkan pada sarana gedung atau penambahan ruangan layanan dalam memenuhi kebutuhan pengguna yangsemakinkompleks. Perubahan konten merujuk kepada penambahan bentuk koleksi. Di era digital ini dengan pengguna yang digital native perpustakaan harus memiliki koleksi elektronik (e-publications). Melihat perkembangan perpustakaan itu sendiri, ada penambahan makna dari perpustakaan.
Sebelum era digital, perpustakaan dengan koleksicetak seringdisebut dengan perpustakaan konvensional.Namun saat ini perpustakaan yang memiliki koleksi cetak dan elektronik disebut dengan perpustakaan hibrida. Perpustakaan hibrida adalah perpustakaan yangmemiliki koleksi tercetak yang permanen dan setara dengan koleksielektronik atau digitalnya (Pendit, 2007, hal.35). Transformasi perpustakaan tidak hanya berhenti di situ saja. Hal ini sangat dirasakan sekali oleh perpustakaan perguruan tinggi yang memiliki pengguna mahasiswa, yang mana mereka adalah digital native. Karakteristik digital native menurut Strauss and Howe dikutip oleh Gibbons, seperti yang tergambar dibawah ini

When net generation students come to campus, they naturally expect the special treatment to continue. Wager suggests that one manifestationof this attitude is

* Pustakawan Perpustakaan Universitas Airlangga

E-mail: sulis.syama@gmail.com 
that college "students want customizedandpersonalized services, not a one-size-fits-all approach. There islittle question that the net generation has expectationsthatare more encompassing, and perhaps moredemanding, than those of previous generations. these expectationsextend to all parts of campus, including the library (Gibbons, 2007, hal. 15).

Perilaku mahasiswa generasi net memilikiperilaku yang individualistik ingin diperlakukan secara khusus dengan layanan yang disamakan dan bersifat pribadi, bukan pendekatan satu untuk semua. Dan mereka memiliki harapan yang lebih luas, dan mungkin lebih menuntut dari generasi sebelumnya, dan harapan ini ditujukan ke semua kampus termasuk perpustakaan. Generasi net juga memiliki bakat yang lebih atau multitasking. Mereka juga mampu mengerjakan banyak tugas sekaligus dengan mudah, seperti menulis bisa melakukan satu atau lebih percakapan melalui pesan instan, bahkan mendengarkan musik, dan menonton program televisi (Gibbons, 2007, hal. 17).

Melihat kondisi di atas mulai perubahan atau penambahan koleksi, media teknologi informasi dan komunikasi sampai dengan karakteristik pengguna "Digital native" merupakan tantangan yang besar bagi perpustakaanperguruantinggisaat ini.Makaperpustakaan perguruan tinggi sebagai jantung informasi harus melakukan transformasi atau perubahanuntukmemenuhi kebutuhan informasipenggunanya. Agar tidak terlindas oleh perubahan zaman. Sebagaimana yangdisampaikan oleh Sekretaris Jenderal Kementerian Riset, Teknologi dan Pendidikan Tinggi (Kemenristekdikti) Bapak Ainun Na'im dalam acara Workshop Kepustakawanan dan Rapat Kerja Forum Kerja sama Perpustakaan Perguruan Tinggi Negeri pada tanggal 22 Maret 2018 bahwa perpustakaan harus bertransformasi mengikuti perkembangan teknologiagar dapat menjawabkebutuhan masyarakat. "Perpustakaan ke depannya tidak hanya menjadi tempat berkumpuluntuk membacabukuataupun mencari informasi, namun perpustakaan dapat menjadi “working space" tempat munculnya inovasi-inovasibaru. Perpustakaan juga dapat menjadi suatu "virtual office". Dan disampaikan oleh Beliau bahwa perpustakaan perguruan tinggi mempunyai 'available space' yang lebih banyak, sehingga ruangannya dapat diubahmenjadi tempat pertemuan yangnyaman bagi “innovators" dan atau "technoentrepreneur" berbasis "virtual office". Atmosfer perpustakaan yang sarat dengan "knowledge" akan menginspirasi para "technoentrepreneurs"muda untuk menghasilkan inovasi-inovasi baru dalam bidangnya. Di luar negeri, beberapa Negara telah mengoptimalkan pemanfaatan ruangpustaka sepertiitu, dan saya rasa di Indonesia, hal ini patut di coba', sebut Sekjen Ainun Na'im (https://www.facebook.com/taufiq. abdulgani/posts/10216290465633358).

Perpustakaan Universitas Airlangga dalam beberapa tahun terakhir ini telah melakukan berbagaitransformasi baik secara fisik (infrastruktur) maupun konten. Dan seperti yang telah disampaikan oleh Bapak Ainun Na'im di atas, Sebenarnya Perpustakaan Universitas Airlangga telah memiliki "available space" dalam menunjang kegiatan pembelajaranmahasiswa. “Available space” seperti apakah yang dimaksud (konsep) dan bagaimana pemanfaatannya di Perpustakaan Universitas Airlangga Surabaya.Untuk itu, penulis tertarik untuk mengidentifikasidan menganalisis upaya yangdilakukan perpustakaan perguruan tinggi dalam menciptakan “available space”. Secara khusus, lokasi penelitian yang dikaji adalah "available space” di Perpustakaan Universitas Airlangga Surabaya.

\section{TINJAUAN PUSTAKA}

\section{Perpustakaan Perguruan Tinggi sebagai "Availabe space"}

\section{Pengertian "Available Space”}

Seperti yang disampaikan oleh Bapak Sekjen KemenristediktiBapak Ainun Na'im bahwaperpustakaan perguruan tinggidiera digitalharus memiliki “available space”. Apa yang dimaksud dengan “available space” itu sendiri. Belum ada atau banyak literatur perpustakaan yang membahas tentang konsep “availablespace”secara khusus tetapi pengertian space (tempat) secara umum untuk era net generation. Pengertian “available space” itu sendiri secara leksikal dalam bahasa Inggris, berasal dari dua kata yang terpisah yaitu "available” yang artinya tersedia dan "space” artinya ruangan. Maka penulis menyimpulkan yangdimaksud dengan "available space" di atas adalah sebuah ruangan yang tersedia di perpustakaan yangbisa atau dapat mengakomodir bakat dan minat pengguna khususnya mahasiswa.

Mahasiswa "Net Generation" adalah mahasiswa mobile, dari pengamatan penulis para pengguna (mahasiswa) yangberkunjungke perpustakaanlebihaktif dengan dunia gadget nya baik itu hand phone, laptop, kamera digital. Kehidupan mereka tidak bisa lepas dari perangkat portable storage dan wireless connection. Mereka lebih banyak menghabiskan waktu mereka 
mengonsumsimedia dan informasididunia maya. Baik itu informasisosial mereka maupun kegiatan akademis.

Mereka juga membutuhkan sebuah tempat dimana secara leluasa dapat melakukan aktivitas merekaselama

di kampus seperti membaca, makan, minum, tidur, bersosialisasi, terlibat dalam kelompok dan belajar individu. Di samping itu mereka dapat mengakses informasidengan gadget mereka baik untuktujuansosial maupun akademis.

Hal iniharus disadarioleh perpustakaan perguruan tinggi yang tidak hanya mengadakan, mengumpulkan, mengolah, dan menyebarluaskan informasisajaagarselalu eksis tidak terlindas oleh jaman. Tepatnyaperpustakaandi jaman “Net Generation" perpustakaan perguruantinggi sebagai tempat yang mana para penggunanya(mahasiswa) dapat melakukan aktivitas belajar, penelitian, dandiskusi dari berbagai disiplin ilmu (Gibbons, 2007, hal. 94). Perpustakaan seperti apa yangdiharapkan oleh mereka. Tepatnya perpustakaan kampus atau perguruan tinggi adalah harapan mereka sebagai tempat pembelajaran yang nyaman dan menyenangkan karena memiliki jam operasional yang panjang dan memiliki banyak tempat duduk. Menurut Gibbons (2007, hal. 94) melihat fungsi perpustakaan diatas, akibatnya perpustakaantidakhanya mempunyai tempat yanghanya untuk penelitian, belajar, dan keahlian akademik lainnya. Namun perpustakaan perguruan tinggi harus memiliki pemikiran peran yang cukup luas dan mendapatkan implikasi untukfasilitas, kebijakan, dan teknologi apa yang ditawarkan dan bagaimana. “Available space” merupakan fasilitasyang harus disediakan oleh perpustakaan perguruan tinggi saat ini baik dalam bentuk ruang publik (public space) dan ruangpribadi(private space). Yangsifatnyaterbuka untuk aktivitas akademika dan kemanfaatannya lebih mengarah kepada pembelajaran, diskusi, sharing information, dan pengembangan minat dan bakat.

\section{Public Space (Ruang publik)}

Melihat perkembangan perpustakaan perguruan tinggi saat ini dituntut untuk selalu mengalami transformasi (perubahan) baik karena tuntutan jaman dan kebutuhan penggunanya. Dan sekarang ini perpustakaan perguruan tinggi saling berpacu dalam melakukan perubahan darikoleksi, layanan, gedung, dan ruangan dengan alokasianggaran yangtelah ditentukan. Tanpa adanya perubahan, peran perpustakaanperguruan tinggi akan hilang keberadaannya. Peran perpustakaan perguruan tinggiyangsangat besar dalam mencerdaskan kehidupan bangsa dan secara tidak langsung ikut melahirkan lulusan-lulusan universitas yang unggul dan berkompeten di masyarakat. Peran perpustakaan perguruan tinggi tertuang dalam TRIDHARMA PERGURUAN TINGGI, yang mendukung dan menunjang kinerja perguruan tingginya yaitu sebagai :

1. Sebagai penunjang pendidikan dan pengajaran. Perpustakaan Perguruan Tinggi bertujuan untuk mengumpulkan, mengolah, menyimpan, menyajikan dan menyebarluaskan informasiuntukmahasiswadan dosen sesuai dengan kurikulum yang berlaku

2. Sebagaipenunjangpenelitian. Kegiatan Perpustakaan Perguruan Tinggiadalah mengumpulkan, mengolah, menyimpan, menyajikan dan menyebarluaskan informasi bagi peneliti baik intern institusi atau ekstern di luar institusi

3. Sebagai penunjang pengabdian kepada masyarakat. Perpustakaan Perguruan Tinggimelakukan kegiatan dengan mengumpulkan, mengolah, menyimpan, menyajikan dan menyebarluaskan informasi bagi masyarakat (Santi, 2014, hal. 168)

Untuk tercapainya visi dan misi tersebut menurut Sulistyo-Basuki maka tujuan perpustakaan perguruan tinggi adalah sebagai berikut:

1. Memenuhi keperluan informasi masyarakat perguruan tinggi, lazimnya staf pengajar dan mahasiswa. Sering pula mencakup tenaga kerja administrasi perguruan tinggi.

2. Menyediakan bahan pustaka (referensi) padasemua tingkatan akademis, artinya mulai dari mahasiswa tahun pertama hingga ke mahasiswa pascasarjana dan pengajar.

3. Menyediakan ruangan belajar bagi pemakai perpustakaan.

4. Menyediakan jasa peminjaman yang tepat gunabagi berbagai jenis pemakai.

5. Menyediakan jasa informasi aktif yang tidak saja terbatas pada lingkungan perguruan tinggi juga lembaga industri lokal (Santi, 2014, hal. 168-169)

Perpustakaan perguruan tinggi saat ini dituntut untuk menyediakan ruangan belajar bagi penggunanya yang dapat memfasilitasiaktivitas pengguna yang serba digital. Penyediaan ruang belajar yang nyaman dan menyenangkan adalah harapan dan keinginan mereka agar dapat mengeksplor potensiyang mereka milikibaik secara berkelompok maupun pribadi. Public space dan private space adalah ruangan yang sangat mendukung kegiatan mereka. 
Menurut Jurgen Habermas, yangdimaksud dengan ruangpublik adalah sebuah tempat untuk berkumpulnya masyarakat yang memiliki kebebasan menyatakan pendapat, sikap, dan memberikan argumen tanpa adanya pengaruh atau tekanan daripihak yangberkuasa (Qomariyah, 2017, hal. 29).

Sebagai "public space" ruangan yang disediakan oleh perpustakaan perguruan tinggi mendukung untuk pembelajaran secara kolaboratif. Mengingat perguruan tinggi merupakan tempat pendidikan yang memiliki berbagai fakultas dan program studi dari berbagai disiplin ilmu. Maka perpustakaan perguruan tinggi merupakan tempat berkumpulnya (meeting point) para pengguna dariberbagaifakultas dan program studi yang ada diperguruan tinggi tersebut. Tentunya ada berbagai kegiatan yangbersifat kolaboratif baik secara akademik maupun non akademik diperpustakaan perguruan tinggi tersebut yang sifatnya terbuka untuk civitas akademika dari semua fakultas, strata mulaidiploma sampai dengan pasca sarjana (Istiana, 2015, hal. 42).

Begitu pentingnya "public space" ini bagi mahasiswa dalam mendukung pembelajaran mereka. Seperti apakah "public space” yang diharapkan oleh pengguna (mahasiswa) di era generasi net ini. Menurut Stephen Carr et al., bahwa "public space" yang bisa berfungsi secara optimal dan berperan baik, maka "public space" harus memiliki 3 (tiga) kualitas utama yaitu:

1. Responsive (tanggap) atinya "public space" harus dirancangdan dikelola dengan mempertimbangkan kepentingan penggunanya

2. Democratic (demokratis) atinya hak penggunayang menggunakan ruangan public atau "public space" harus dilindungi, para pengguna bebas untuk berekspresi di ruangan tersebut namun harus tetap dalam batas aturan yang ada dan telah ditetapkan oleh perpustakaan tersebut. Karena "public space" adalah ruangan bersama dan terbuka untuk para pengguna lainnya yangjuga memanfaatkan ruangan tersebut

3. Meaningful (bermakna) artinya "public space" paling tidak memiliki ikatan emosional dengan kehidupan penggunanya. Ruangan tersebut harus berkesan pengguna yang menggunakan ruangan tersebut merasa betah, nyaman, dan menyenangkan sehingga pengguna dapat leluasa untuk berekspresi (Qomariyah, 2017, hal. 26-27).

Disamping tiga halkualitas utama yangdisebutkan di atas, menurut Stephen Carr et al., dalam Mathew
Carmona et. al. berpendapat bahwa "public space" (ruang publik) dapat termanfaatkan secara optimal dan berperan baik bilamana memuat unsur:

1. Kenyamanan (Comfort) merupakan syarat utama yangharus diperhatikan dalam mengadakan "public space”. Karena pengguna akan merasa nyaman apabila ruangan publik tersebut dapat mendukung segala aktivitas pengguna, yang perlu diperhatikan adalah

a. environmental comfort (lingkungan yang nyaman). Ruangan publik harus terlindungioleh pengaruh alam seperti matahari, hujan, dan angin.

b. physical comfort tersedianya tempatduduk, meja, ruangan ber $\mathrm{AC}$ untuk menjaga kesejukanruangan serta sarana presentasi atau multimedia seperti LCD projector. Dan yang terpenting adalahsteker meskipun halyangsepele tetapi sangatdibutuhkan oleh mahasiswa generasi net.

2. Social and psychological comfort ruangpublikdapat memberikan

a. effort self-confidence (kekuatan) rasapercayadiri pengguna untuk berekspresi dan bersosialisasi.

b. relaxation dengan penataan ruangan publik yang menarik dengan menghadirkan suasana penghijauan (taman), miniatur (airmancur, patung, kolam ikan), jauh dari polusi suara (keramaian kendaraan) dapat membawa dampak psikologis pikiran dan badan menjadi sehat dan senang.

3. Passive engagement perilaku pasif dipengaruhi oleh kondisi sekitarnya. Dimana pengguna dapat melakukan aktivitas duduk-duduk atau berdiri sambil melihat keindahan sekitarnya seperti taman, air mancur, kolam ikan atau patung

4. Active engagement perilaku aktif dapat dikatakan berhasil apabila ruang publik tersebut dapat memberikan suasana atau mewadahi komunikasi antar anggota masyarakat baik teman, famili atau orang asing dengan baik.

5. Discovery ruang publik ditata secara tidak monoton agar tidak timbul rasa kebosanan bagi aktivitas penggunanya (Qomariyah, 2017, hal. 27). Aktivitas mahasiswa generasinet sangat tinggidalamperolehan informasinya serta kehidupannya yang tidak bisa ditinggalkan dengan dunia gadget maka "public space" (ruang publik) harus dilengkapi dengan

6. Wireless connection atau Wifi zone, Wifi adalah sebuah teknologi yang memanfaatkan peralatan elektronik untuk bertukar data secara 
nirkabel (menggunakan gelombang radio) melalui sebuah jaringan komputer, termasuk koneksiinternet berkecepatan tinggi (https://id.wikipedia.org/wiki/ $\mathrm{Wi}-\mathrm{Fi}$ ).

7. Capacity ruang publik juga harus diperhatikan kapasitas atau daya tampung pengunjung yang menggunakan ruangan publik tersebut. Ruang publik dengan ukuran yang lebih luas dapat menampung jumlah pengguna lebih dari 20 orang akan memungkinkan pengguna lebih efektif dalam penggunaannya. Karena mahasiswa generasi net lebih menyukai pembelajaran secara berkelompok, berdiskusi, dan sharing informasi

8. Permissions perijinan atau kemudahan juga harus diperhatikan dalam penggunaan ruang publik. Perijinanyangtidakberbelit-belitdenganaturan-aturan yang masih bisa diberlakukan, memungkinkan mahasiswa lebih efektif dalam penggunaannya.

\section{Private Space (Ruang Individu)}

Perpustakaan perguruan tinggiselain menyediakan ruang publik (public space) yangsifatnya lebih terbuka dan luas. Manajemen perpustakaan juga memikirkan bagi mereka yang ingin belajar individu tanpa ada gangguan dari pihak mana pun biasanya membutuhkan konsentrasi yang tinggi dan serius dalam belajar, jauh dari kebisingan, dengan menyediakan ruang individu (Private Space). Ruang individu memilikiruangan yang lebih kecil hanya menampung satu pengguna saja. Dan lebih bersifat silent room.

Penggunaan Private Space (Ruang Individu)lebih efektif maka harus memperhatikan dan mempertimbangkan unsur-unsur yang tidak jauh dari ruang publik di atas:

1. Kenyamanan

a. environmental comfort (lingkungan yang nyaman). Ruangan privat harus terlindungi oleh pengaruh alam seperti matahari, hujan, dan angin.

b. physical comfort tersedianya tempat duduk, meja, ruangan ber AC untuk menjaga kesejukan ruangan, steker, pencahayaan yang terang

2. Wireless connection fungsinya juga sama dengan ruang publik ( public space). Tersedianya Wifi, dimana pengguna ruang individu dapat melakukan berbagai kegiatan yang membutuhkan "Daring (Dalam Jaringan)"

\section{Perijinan yang tidak berbelit-belit}

Dengan memperhatikan unsur di atas dan desain ruang publik serta ruang individu yang sangat menarik akan menambah nilai manfaat perpustakaan itu sendiri. Perpustakaan perguruan tinggi tidak hanya sebagai wadah pengelola informasi tetapi juga "available space" yangdapat menyinergikan calon-calon ilmuwan dalam berkolaborasi untuk menghasilkan suatu karya anak bangsa. Inilah yang harus kita pikirkan di era $\boldsymbol{n e t}$ generation yang lebih aktif dengan gadget. Tentunya kita sebagai pustakawan harus menjembatani atas kreativitas mereka, dengan ketersediaan fasilitas-fasilitas perpustakaan.

\section{METODE}

Artikel ini ditulis oleh penulis berdasarkan teori yangditemukan daribeberapa literatur, pengamatan, dan pengumpulandata-datayangdiperolehdarisumbermedia sosial serta laporan penggunaan ruang(ruangindividu). Menurut Sugiyono (2010, hal. 147) analisis deskriptif adalah menganalisis data dengan cara mendeskripsikan atau menggambarkan data yang telah terkumpul sebagaimana adanya tanpa bermaksud untuk membuat kesimpulan yang berlaku umum atau generalisasi.

\section{PEMBAHASAN}

\section{Ruang Publik}

Perpustakaan Universitas Airlangga Surabayauntuk mendukung kegiatan civitas akademika telah melakukan berbagai transformasi dalam penataan ruangan dengan tujuan memfasilitasipara pengguna dalam mengeksplor akademik, minat, dan bakat mereka. Ruang publik yang ada di Perpustakaan Unair bersifat terbuka bagi siapa saja yang ingin menggunakan ruangan tersebut namun harus tetap dalam norma-norma (kesopanan) yangtelah ditetapkan. Ruangpublik dapatdigunakansewaktu-waktu selama tidak ada kegiatan yangbersifat urgent (penting) penggunaannya yang membutuhkan kapasitas pengguna yanglebih banyak (20-100) peserta dan digunakandalam seharian.

Ruang publik di Perpustakaan Universitas Airlangga terdiri dari: 
Kegiatan di Ruang Lobby Perpustakaan Unair Tahun 2018

\begin{tabular}{|c|c|c|c|c|c|}
\hline No. & Tanggal & Kegiatan & Penyelenggara & Pengisi Acara & Ket \\
\hline 1 & 15 Januari 2018 & $\begin{array}{l}\text { Musicoustic Airlangga } \\
\text { Orkestra }\end{array}$ & $\begin{array}{l}\text { HUMAS } \\
\text { PERPUSTAKAAN } \\
\text { UNAIR }\end{array}$ & Airlangga Orkestra & $\begin{array}{l}\text { Minggu ke } 3 \\
\text { per bulan }\end{array}$ \\
\hline 2 & $\begin{array}{l}\text { 12-15Februari } \\
2018\end{array}$ & $\begin{array}{l}\text { Festival Bursa Buku } \\
\text { Seken }\end{array}$ & PanitiaHUT PUA ke-63 & $\begin{array}{l}\text { Partisipan } \\
\text { (Mahasiswa) }\end{array}$ & \\
\hline 3 & 26 Maret 2018' & Musicoustic H - 1 Squad & $\begin{array}{l}\text { HUMAS } \\
\text { PERPUSTAKAAN } \\
\text { UNAIR }\end{array}$ & MAHASISWA FEB & $\begin{array}{l}\text { Minggu ke } 3 \\
\text { per bulan }\end{array}$ \\
\hline
\end{tabular}

Sumber: https://www.facebook.com/unairlibrary/

\section{A. Ruang Lobby Perpustakaan Universitas Airlangga}

Ruang lobby Perpustakaan Unair berada di lantai 1 depan pintu masuk perpustakaan. Tahun ini(2018)telah diadakan berbagai kegiatan dalam 1 (satu) bulan sekali diakhir bulan ketiga dengan mengundang mahasiswa baik secara perorangan maupun kelompok UKM (Unit Kegiatan Mahasiswa). Events yang pernah diadakan di ruang lobby dapat dilihat dalam tabel di bawah ini:

Kegiatan ini sangat menarik dan mendapatkan antusias dari para pengguna Perpustakaan Unair yang membutuhkan refresh (penyegaran) dan entertainment (hiburan). Kebisingan yang dirasakan selama events berlangsung di ruang lobby dapat dikendalikan karena ruang lobby ini berada di lantai 1 jauh dari ruangbaca lantai 2 dan 3. Pengguna yang baru datang ke Perpustakaan Unair dapat menikmati acara tersebut secara langsung dan terbuka.

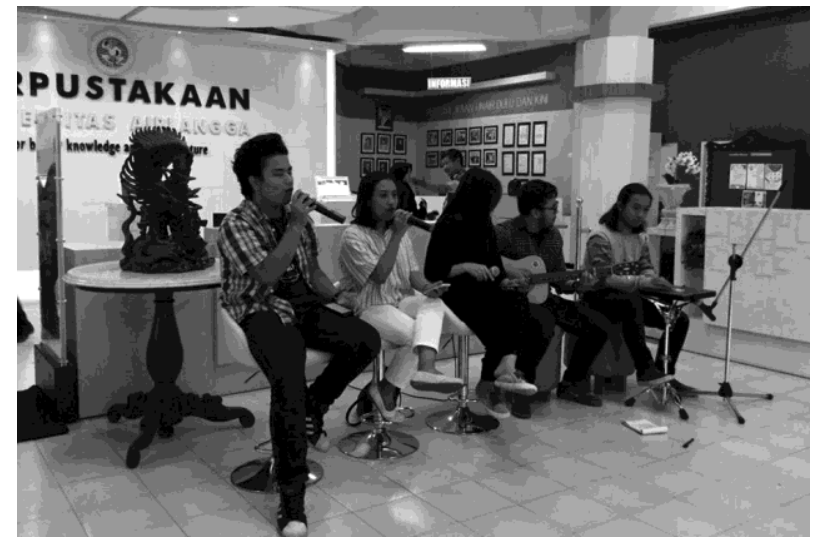

Foto 1. Ruang Lobby Performance dari Airlangga Orchestra

\section{B. Ruang Publik (Diskusi) lantai 1}

Pengguna Perpustakaan Unair saat ini merupakan pengguna yanglahir diera net generation atau generasi millennial, dimana pola belajar mereka dilakukan secara individu maupun berkelompok (diskusi). Perpustakaan Unair menyediakan fasilitas Ruang Publik (Diskusi) di lantai 1. Terkadang ruangan publik juga sering dimanfaatkan untuk implementasikegiatan perkuliahan mahasiswa. Berbagai kegiatan yang pernah dilakukan oleh pengguna Perpustakaan Unair dapat dilihat pada tabel Kegiatan di Ruang Publik (Diskusi) lantai 1.

\section{Ruang Belajar Individu (Rubelin)}

Perpustakaan Universitas Airlangga juga menyediakan fasilitas Rubelin (Ruang Belajar Individu) manfaatnya untuk pengguna yang membutuhkan

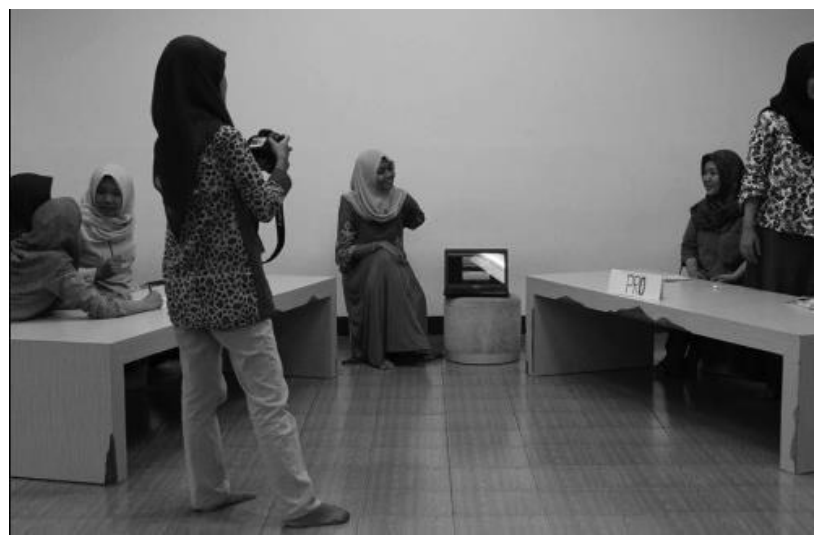

Foto 2. Ruang Publik (Diskusi): Kompetensi Debat atau belajar untuk persiapan sidang tesis 
Kegiatan di Ruang Publik (Diskusi) lantai 1

\begin{tabular}{lclll} 
No. & \multicolumn{1}{c}{ Tanggal } & \multicolumn{1}{c}{ Kegiatan } & \multicolumn{1}{c}{ Penyelenggara } & Pengisi Acara \\
\hline 1 & 23 Maret 2018 & Belajar bersama menghadapi UTS & $\begin{array}{l}\text { Mahasiswa } \\
\text { PanitiaHUT PUAke-63 } \\
\text { bersama PMI }\end{array}$ & $\begin{array}{l}\text { Mahasiswa } \\
\text { PMI bersama } \\
\text { sponsor }\end{array}$ \\
3 & 08 Maret 2018 & Donor Darah & Mahasiswa & Mahasiswa \\
4 & 20 Pebruari 2018 & $\begin{array}{l}\text { Belajar Bahasa Inggris dan Perancis } \\
\text { Pelatihan Story Telling Bagi Pustakawan } \\
\text { dan Guru Paud/TK Taman Baca Binaan }\end{array}$ & Panitia HUT PUA ke-63 & Handoko \\
5 & 20-Des-17 & Pelatihan KompetisiDebat Sidang Thesis & Mahasiswa & Mahasiswa \\
\hline
\end{tabular}

Sumber: https://www.facebook.com/unairlibrary/

ketenangan belajar, belajar sendiri tanpa diganggu oleh rekan-rekannya. Ruangan ini selalu penuh digunakan pada saat-saat menjelang ujian tengah semester, ujian akhir, semester, maupun menghadapiujian sidangtugas akhir. Pemesanan rubelin tidak berbelit-belit, cukup mudah dan bisa dilakukan secara langsung(on the spot) melaluibagian Humas (Informasi) maupunmendaftarkan diri di web www.lib.unair.ac.id.

Prosedur penggunaan Rubelin:

1. Pengguna harus menunjukkan dan meninggalkan KTM (Kartu Tanda Mahasiswa)

2. Pengguna mengisi form yang tersedia di web Perpustakaan Unair www.lib.unair.ac.id

3. Petugas akan memberikan kuncirubelin

Untuk sementara ini penggunaan Rubelin hanya diperuntukkan untuk civitas akademika Unair saja karena hanya tersedia 4 (empat) rubelin saja. Fasilitas yang tersedia di Rubelin meliputi meja pengguna, kursi pengguna, lampu belajar, steker, ruangan berAC,karpet, dan Wifi.

\section{Ruang Parlinah Moedjiono}

Ruang Parlinah di lantai 3, disediakan oleh Perpustakaan Unair untuk kegiatan-kegiatan yang melibatkan peserta kurang lebih 100 peserta. Ruangan inidapat dimanfaatkan juga oleh pengguna Perpustakaan Unair baik dari dalam maupun luar civitas akademika. Kegiatan yang sering dilakukan di Ruang Parlinah Moedjiono seperti seminar, workshop, lokakarya, talkshow, diskusi, maupun unjuk prestasi (Challenge). Rangkaian kegiatan yang dilakukan di Ruang Parlinah dapat dilihat di tabel Kegiatan Ruang Parlinah.

Penggunadaridalam maupun luarcivitasakademika Unair dapatmemanfaatkanruangpublik tersebut, dengan melalui berbagai prosedur yang harus mereka taati dan patuhi. Untuk kesehariannya ruang publik ini berada di bawah tanggung jawab bagian Humas Perpustakaan Universitas Airlangga. Dan penggunadapatmenghubungi secara langsungke bagian Humas Perpustakaan Unairdi jam kerja.

Kesediaan ruangpublik ini sudah banyak pengguna yang mengetahui fasilitas tersebut. Sebagaimana yang dijelaskan oleh Saudara Agung Budi Kristiawan selaku penanggung jawab Humas, pengguna sudahbanyakyang mengenal fasilitas ruang publik ini dari mulut ke mulut. Bahkan pihak humas sendiri jarang mempromosikan ruang publik tersebut kepada para pengguna melalui media sosial. Mungkin dari pengenalan kepada MABA (Mahasiswa Baru) kita telah menjelaskan kepadamereka tentang fasilitas Perpustakaan Unair yangtersedia. Dari P3MB (Program Pengenalan Pada Mahasiswa Baru) mereka mengetahui secara langsung.

Namun untuk pemanfaatan yang lebih maksimal terhadap ruang publik perlu adanya promosi kepada pengguna di luar civitas akademika. Dengan demikian Perpustakaan Unair dapat lebih dikenal dan memiliki nilai lebih di luar masyarakat Unair.

\section{KESIMPULAN}

Ruang publik harus ditata dan dikelola sedemikian rupa agar para pengguna perpustakaan merasa betah untuk berkunjung ke perpustakaan, mereka tidak hanya untuk belajar tetapi juga bersosialisasi dan mengembangkan minat dan bakat mereka. Maka sepatutnya perpustakaan perguruan tinggi lebih memiliki rasa kedekatan kepada penggunanya guna memenuhi kebutuhan apa yang diinginkan penggunanya di era generasi net atau millennial sekarang ini. 


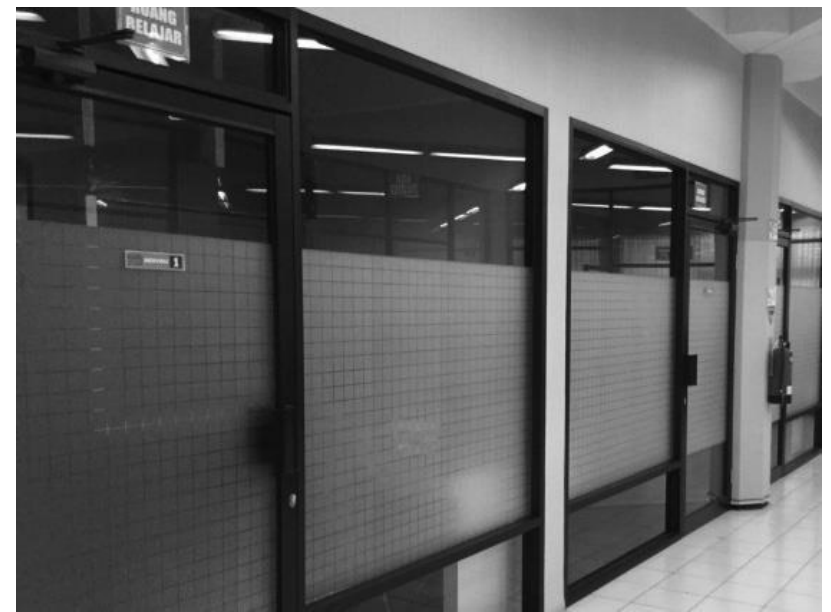

Foto 3. Ruang Belajar Individu.

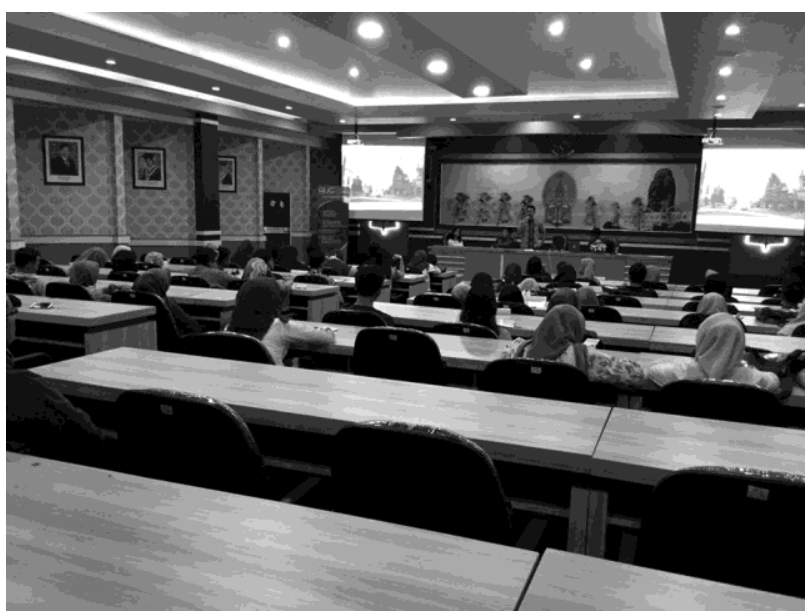

Foto 4. Sharing Session Airlangga Global Engagement.

Kegiatan di Ruang Parlinah

\begin{tabular}{|c|c|c|c|c|}
\hline No. & Tanggal & Kegiatan & Penyelenggara & Pengisi Acara \\
\hline 1 & 27 Maret 2018 & $\begin{array}{l}\text { Pelatihan Performa Staf perpus dan } \\
\text { Ruang baca Fakultas se-UNAIR }\end{array}$ & $\begin{array}{l}\text { Manajemen Perpustakaan } \\
\text { Unair }\end{array}$ & $\begin{array}{l}\text { Motivator Adri Suyanto } \\
\text { Didik Pribadi }\end{array}$ \\
\hline 2 & 27 Pebruari 2018 & Sharing session & $\begin{array}{l}\text { Airlangga Global } \\
\text { Engagement }\end{array}$ & $\begin{array}{l}\text { Airlangga Global } \\
\text { Engagement }\end{array}$ \\
\hline 3 & 7 Maret 2018 & Parenting Seminar & Panitia HUT PUA ke-63 & \\
\hline 4 & 6 Maret 2018 & $\begin{array}{l}\text { Workshop Manajemen } \\
\text { Perpustakaan Sekolah }\end{array}$ & Panitia HUT PUA ke-63 & Tim PanitiaHUT PUA \\
\hline 5 & 8 Maret 2018 & $\begin{array}{l}\text { Talk show Menulis Skripsi dengan } \\
\text { Cepat dan Tepat }\end{array}$ & Panitia HUT PUA ke-63 & $\begin{array}{l}\text { Narsum Kak Rosa dan } \\
\text { Kak Tasia }\end{array}$ \\
\hline 6 & 8 Desember 2017 & $\begin{array}{l}\text { Diskusi Buku: Dibalik Krisis } \\
\text { Ekosistem, Pemikiran tentang } \\
\text { Kehutanan dan Lingkungan Hidup } \\
\text { dalam rangka Pekan Hari Hak } \\
\text { Asasi Manusia }\end{array}$ & $\begin{array}{l}\text { Huma (Perkumpulan } \\
\text { untuk Pembaharuan } \\
\text { Hukum Berbasis } \\
\text { Masyarakat dan Ekologis) }\end{array}$ & HUMA \\
\hline 7 & 14 November 2017 & $\begin{array}{l}\text { Entrepeneur Poser: Modal Bisnis, } \\
\text { bagaimana caranya? }\end{array}$ & $\begin{array}{l}\text { PPKK, Bank BNI dan } \\
\text { Peduli Indonesia }\end{array}$ & $\begin{array}{l}\text { PPKK, Bank BNI dan } \\
\text { Peduli Indonesia }\end{array}$ \\
\hline 8 & 9 November 2017 & Airlangga Go Talent 2017 & HUMAS UNAIR & HUMAS UNAIR \\
\hline
\end{tabular}

Sumber: https://www.facebook.com/unairlibrary/ 


\section{DAFTAR PUSTAKA}

Gibbons, S. 2007. The Academic Library and The Net Gen Student: Making the Connections. Chicago:American Library Association.

Istiana, P. 2015. Pubic Space dan Private Space : Posisi Strategis Perpustakaan dalam Mendukung Pembelajaran Kolaboratif. Jurnal Pustaka Ilmiah : Jurnal Ilmiah UPT Perpustakaan UNS , 1 (1), 42.

Kalida, M. 2015. Capacity Building perpustakaan. Yogyakarta: Aswaja Pressindo.

Pendit, P. L. 2007. Perpustakaan Digital: Perspektif Perpustakaan Perguruan Tinggi Indonesia. Jakarta: CV.Sagung Seto.

Qomariyah, A. N. 2017. Upaya Perpustakaan Perguruan Tinggi Dalam Menciptakan Ruang Publik: Kajian “wifi zone corner" di Perpustakaan ITS. Pustakaloka, 26-27.

Santi, T. 2014. Transformasi Perpustakaan UIN SUKA Menuju Layanan yang Berkualitas. Jurnal Iqra, Volume 08 (No.02), 168-169.

Sugiyono.2010. Metode Penelitian Kuantitatif, Kualitatif dan $R \&$ \& . Bandung: Alfabeta.

\section{INTERNET}

https://id.wikipedia.org/wiki/Wi-Fi. (n.d.).

https://www. facebook. com/taufiq.abdulgani/ posts/10216290465633358.(n.d.).RetrievedMaret 27, 2018 